Original Article

\title{
Outcome of Minigrafting In Stable Vitiligo: An Insight from Libya
}

\author{
Fauzia Musbah (it) \\ Department of Dermatology, Faculty of Medicine, University of Tripoli, Tripoli, Libya. \\ Corresponding e-mail: fauziamusbah@yahoo.com
}

\begin{abstract}
Background and aims. Autologus with punch minigrafting has been suggested as an alternative surgical method for treating stable vitiligo in refractory patients to induce regimentation. The current study was conducted to evaluate the long-term results of surgical punch minigrafting in patients with resistant vitiligo vulgaris, segmental and focal vitiligo. Methods: Case series prospective exploratory study design was performed in Tripoli central hospital (TCH) and private clinic among patient with confirmed vitiligo vulgaris, segmental and focal vitiligo, during the period from 2009 -2019. Data were presented as descriptive statistics using SPSS version 22. Chi-square test was used to test the significance of data with the level of 0.05 considered as significant level. Results: A total of 28 patients presented with vitiligo, of them 26 (92.9\%) were females and $2(7.1 \%)$ were males, with age ranging from 11-46 years old. The re-pigmentation of vitiligo was $(53.6 \%)$ vulgaris, $(28.6 \%)$ segmental, and $(17.9 \%)$ focal vitiligo, with stable disease that did not have any new lesions at least 12 months with the disease ranging from one year $(7.2 \%)$ and up to 30 years. The main instruments used with these cases were; skin punch size between $2 \mathrm{~mm}(28.6 \%), 2.5 \mathrm{~mm}(32.1 \%)$, and 4 to $6 \mathrm{~mm}(10.7 \%)$. The donor sites where selected to match the recipient sites either behind ear $39.3 \%$, thighs $43 \%$, while $3.6 \%$ were not previously affected by the disease. Conclusion. It has been suggested that mini grafting is a proper treatment option for treating patients with stable vitiligo, by using a small size punch, that is less than $2 \mathrm{~mm}$.
\end{abstract}

Keywords: Punch, Minigrafting, Vitiligo, Vulgaris.

Citation: Fauzia Musbah. Outcome of Minigrafting In Stable Vitiligo: An Insight from Libya. Khalij-Libya J Dent Med Res. 2020;4(2):15-22. https://doi.org/10.5281/zenodo.3988602

Received: 02/08/20; accepted: 12/08/20

Copyright (C) Khalij-Libya Journal (KJDMR) 2020. Open Access. Some rights reserved. This work is available under the CC BY-NC-SA 3.0 IGO license https://creativecommons.org/licenses/by-nc-sa/3.0/igo

\section{INTRODUCTION}

Vitiligo is a result of disrupted epidermal melanization with an undecided etiology and incompletely understood pathogenesis. It has a profound psychological impact and greatly affects the quality of life [1]. Depending on the type, extent, and duration of vitiligo, conventional medical therapies such as topical and systemic corticosteroids, topical immunomodulators, and phototherapy are not always successful, and repigmentation is often incomplete [2].

Vitiliginous lesions occurring on sites such as lips, acral areas, nipples, and genitals are particularly resistant to medical treatment. This has led to the evolution of various surgical modalities to treat recalcitrant stable lesions. Behl et al. 1964 was the first to describe the surgical treatment of vitiligo in a large series of 107 Indian patients with thin Thiersch grafts [3].

The conventional surgical modalities for vitiligo punch grafting, suction blister grafting, and thin split thickness skin grafting were described by Falabella et al. in 1971, were they designated the suction blister technique for repigmentation of vitiligo [4]. Later, the miniature punch grafting technique was developed in 
1978 [5]. Thereafter, in 1989, the use of in-vitro cultures of melanocyte-bearing epidermis for the treatment of vitiligo was implemented [6]. The use of epidermal suspensions obtained by trypsinization was first reported in 1992 by Gauthier and Surleve-Bazeille [7], and further improved by Olsson and Juhlin [8] via adding a melanocyte culture medium for additional growth. Kahn and Cohen [9] utilized the motorized dermatome to obtain ultrathin grafts for vitiligo, and later in 1996 Kahn et al. reported the use of a shortpulse carbon dioxide laser, to denude the recipient area [10]. Subsequently, the excimer laser and targeted phototherapy have been developed to treat vitiligo and mini grafting and NB-UVB [11]. Thus, surgical treatment of vitiligo has evolved over the centuries, even though the etiology and pathogenesis of vitiligo remain elusive.

In 1972, Norman Orentriech first reported auto graft repigmentation in humans. He treated a black woman with longstanding leukoderma, which followed a chemical burn many years back, He reported a maximum of $1 \mathrm{~mm}$ pigment spread from both the 1 and 2mm grafts [12]. In 1976, Labuono and Shatin made a similar observation after transplanting hair bulbs with hair punch grafting within the leucodermic scars of discoid lupus erythematosus (DLE) [13].

Before intending any surgical intervention in vitiligo, a proper assessment of the stability status is important [14]. In clinical situations, stability can be judged by simple indicators; history, lack of progression of old lesions and absence of development of any new lesion within a specified period ( 6 months to 2 years) and absence of a recent Koebner phenomenon. The grafts are placed directly from the donor (buttock/upper thigh) to the recipient areas and finally after 4 to 7 days the dressings have to be removed [15-17]. This speeds up the procedure and lessens the chance of infection. The adhesive gives excellent results to secure the graft and also has antimicrobial properties against staphylococci, pseudomonas, and E. coli [18].

Post-surgically the patients are exposed to PUVA [19, 20]/PUVASOL (Psoralen plus UVA from Sunlight) $[17,21]$ or NB- UVB [11] or even kept as such in some studies [17]. Patients are followed up fortnightly for the initial two months and then monthly, until complete re-pigmentation is achieved, another important parameter was the post-graft appearance of re-pigmentation (AOR) time. It was found to be between 2 and 6 weeks, in different studies, with an overall average being approximately 21.6 days, as shown in one study [22]. The entire depigmented and grafted area is expected to be completely re-pigmenetd within 3-6 months, based on the area of grafting and the body part involved

In the donor site, after healing with secondary intention, minimal superficial scarring is expected and acceptable. Perigraft re-pigmentation is expected to start from around 3-4 weeks [11, 17]. Cobble stoning is regarded as the commonest of them all [11,21,23], It was observed that with time it got corrected in most of the cases. [21] In resistant cases corrective electro fulguration may be needed [24]. In this regard it is only apt to conclude that grafting should not be performed with punches more than $1.5 \mathrm{~mm}$ in diameter. On face and lips, it should be even smaller $(1.2 \mathrm{~mm}$ or $1 \mathrm{~mm})[11,25]$.

\section{METHODS}

Case series prospective exploratory study design was performed in Tripoli central hospital (TCH) and private clinic among patient with confirmed vitiligo vulgaris, segmental and focal vitiligo, during the period from 2009 -2019. Data were presented as descriptive statistics using SPSS version 22. Chi-square test was used to test the significance of data with the level of 0.05 considered as significant level.

\section{RESULTS}

A total of 28 patients presented with vitiligo, of them $26(92.9 \%)$ were females and $2(7.1 \%)$ were males, with age ranging from 11-46 years old. The re-pigmentation of vitiligo was (53.6\%) vulgaris, $(28.6 \%)$ segmental, and $(17.9 \%)$ focal vitiligo, with stable disease that did not have any new lesions at least 12 months with the disease ranging from one year $(7.2 \%)$ and up to 30 years (Table 1). All patients have contact with skin type III $(14.3 \%)$ and type IV $(82.1 \%)$ based on detailed information gathered on the base line and during the follow up. The main instruments used with these cases were; skin punch size between $2 \mathrm{~mm}(28.6 \%), 2.5 \mathrm{~mm}$ (32.1\%), and 4 to $6 \mathrm{~mm}(10.7 \%)$. 
Table 1: Repigmentation grade Crosstabulation

\begin{tabular}{|c|c|c|c|c|c|c|c|}
\hline & & & & epigmen & on gra & & \\
\hline & & & $\begin{array}{c}\text { Excellen } \\
t\end{array}$ & Good & Poor & Regular & Total \\
\hline & & Count & 2 & 2 & 0 & 1 & 5 \\
\hline & focal & $\begin{array}{l}\text { \% within } \\
\text { diagnosis }\end{array}$ & $40.0 \%$ & $40.0 \%$ & $0.0 \%$ & $20.0 \%$ & $100.0 \%$ \\
\hline & & Count & 2 & 2 & 2 & 2 & 8 \\
\hline & Segmental & $\begin{array}{l}\text { \% within } \\
\text { diagnosis }\end{array}$ & $25.0 \%$ & $25.0 \%$ & $25.0 \%$ & $25.0 \%$ & $100.0 \%$ \\
\hline & & Count & 0 & 1 & 0 & 0 & 1 \\
\hline & Vitiligo & $\begin{array}{l}\text { \% within } \\
\text { diagnosis }\end{array}$ & $0.0 \%$ & $100.0 \%$ & $0.0 \%$ & $0.0 \%$ & $100.0 \%$ \\
\hline & & Count & 6 & 5 & 1 & 2 & 14 \\
\hline & vulgaris & $\begin{array}{l}\text { \% within } \\
\text { diagnosis }\end{array}$ & $42.9 \%$ & $35.7 \%$ & $7.1 \%$ & $14.3 \%$ & $100.0 \%$ \\
\hline & & Count & 10 & 10 & 3 & 5 & 28 \\
\hline & & $\begin{array}{l}\text { \% within } \\
\text { diagnosis }\end{array}$ & $35.7 \%$ & $35.7 \%$ & $10.7 \%$ & $17.9 \%$ & $100.0 \%$ \\
\hline
\end{tabular}

The donor sites where selected to match the recipient sites either behind ear 39.3\%, thighs $43 \%$, while $3.6 \%$ were not previously affected by the disease. Regarding the recipient sites, there were $43.1 \%$ affected on the head and neck, $3.6 \%$ on the labia majora, $7.1 \%$ on the areola. Thereafter, surgical grafts were fixed in place in $92.9 \%$, followed by the application of Ezelline solution $2 \%$ and sun exposure for 3 days per a week in most of the patients and $10.7 \%$ of patients used Elidel cream $1 \%$ twice daily. Uniform perigraft pigmentation was obtained during the 4 to 5 weeks, and the results were $92.9 \%$ recurrence of depigmentation in grafted skin in two patients $(7.1 \%)$, and one patient $(3.6 \%)$ was hypothyroid. The re-pigmentation grade was excellent in $35.7 \%$, good in $35.7 \%$, poor in $10.7 \%$ and regular in $17.9 \%$. Excellent re-pigmentation grade was seen in $42 \%$ of vitiligo vulgaris, $40 \%$ of focal vitiligo, and $25 \%$ of segmental vitiligo ( $\mathrm{P}=0.823$ ). Long term follow-up shows that $2.1 \%$ of cases have got re-pigmentation, and $60.7 \%$ presented with cobble stone complication. However, $82 \%$ of the patients didn't developed hypopigmentation or scar.

\section{DISCUSSION}

Vitiligo is a depigmented skin disease with world prevalence estimated between $0.5 \%$ and $2 \%$, and can affect individuals from both genders and all types of skin [26]. It has a considerable effect on patient's quality of life, which can result in social concern, high level of anxiety, and even depression $[27,28]$. Many patients have resisted patches to conventional medicinal modalities and are often unsuccessful indicating the absence of melanocytes reservoir. Surgical treatment may be recommended as a therapeutic option for patients with stable disease and who did not respond well to the other types of treatment.

This study was conducted to explore vitiligo patients with punch minigrafting. The procedure involves the transfer of circular pieces or punches of skin tissue from the donor area into similar shaped pits that are made on the recipient skin. The size of these punches ranged from $2 \mathrm{~mm}$ to $4 \mathrm{~mm}$ and they are spaced 5$10 \mathrm{~mm}$ apart on the recipient skin. Table 2 showing different punch sizes used in different studies. 
Table 2. Punch Graft Size Used

\begin{tabular}{|c|c|c|}
\hline Author (Reference) & year & Punch size diameter in $\mathbf{m m}$ \\
\hline Das SS et al.[29] & 1992 & 4 \\
\hline Jha, et al. [30] & 1992 & 3 and 4 \\
\hline
\end{tabular}

Post operation exposure to ultraviolet light was reported to augment the effect of punch grafting with better and rapid cosmetic result than monotherapy. We have used topical khellin (ezelline solution 2\%), a plant derivative, a furanochromone as photosensitizer plus sun exposure as khellin, and it did not induce skin phototoxicity with UVA, rather re-pigmentation similar to psoralens [31,32]. Some patients have been successfully used topical immunomodulators alone or in combination with other therapeutic modalities [33], for instance; pimecrolimus cream (Elidel) $1 \%$ twice daily especially for patient's skin grafted for head and neck (Figure 1). Most of patients exhibited some degree of improvement which can dramatically improve quality of the life especially when the disease occurs in genitals [34]. Figure 2,4 showed that the patient was evaluated during the period of follow up after the procedure. The graft re-pigmentation is expected to start between $4-5$ weeks which is similar to the reported studies shown in table 3.

Table 3. Appearance of re-pigmentation in different studies.

\begin{tabular}{|c|c|c|}
\hline Athor(reference & year & $\begin{array}{c}\text { Earliest appearance of } \\
\text { repigmentation in days }\end{array}$ \\
\hline Lahiri K, et al. [11] & 2006 & 14 \\
\hline Lahiri K, et al[21]. & 1997 & 14 \\
\hline Malakar S, et al[17] & 1999 & 16 \\
\hline Savant SS[35] & 1992 & 30 \\
\hline
\end{tabular}

The result of excellent repigmentation grade presented in figure 3-6 was $35.7 \%$, and determined by the repigmentation scoring system in previous researches [36].
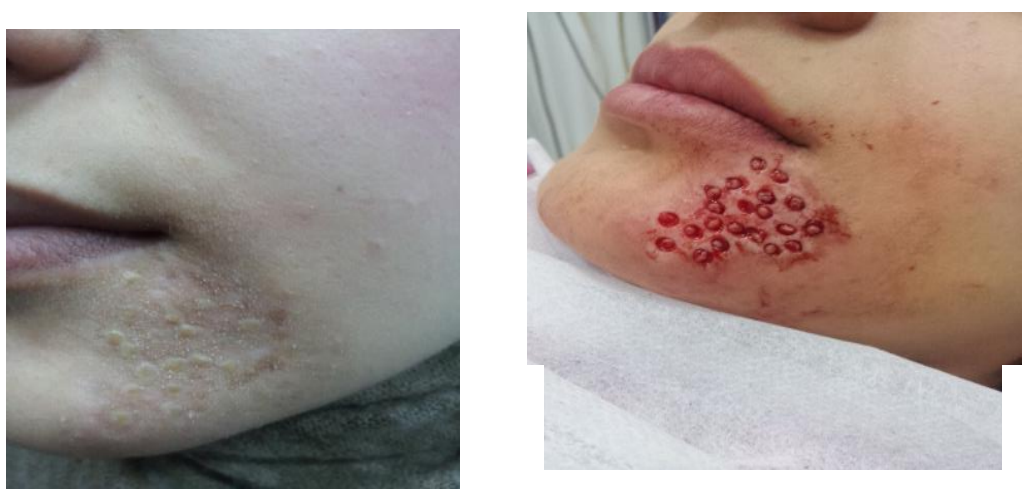

Figure 1: a-Punch grafting2.5mm size on depigmented vitiligo patch at time of surgery. $b$ Cobble stone appearance with excellent repigmentation after 3 months 

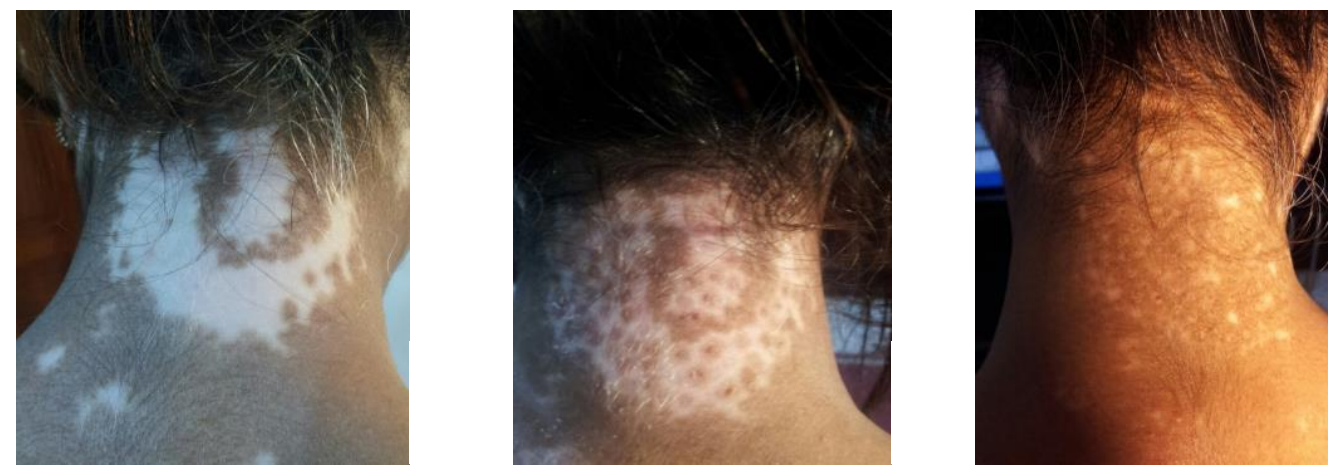

Figure 2: a-Depigmented pataches with vitiligo vulgaris female patient on back of the neck. b- After minigrafting technique. C-Repigmentation after one year
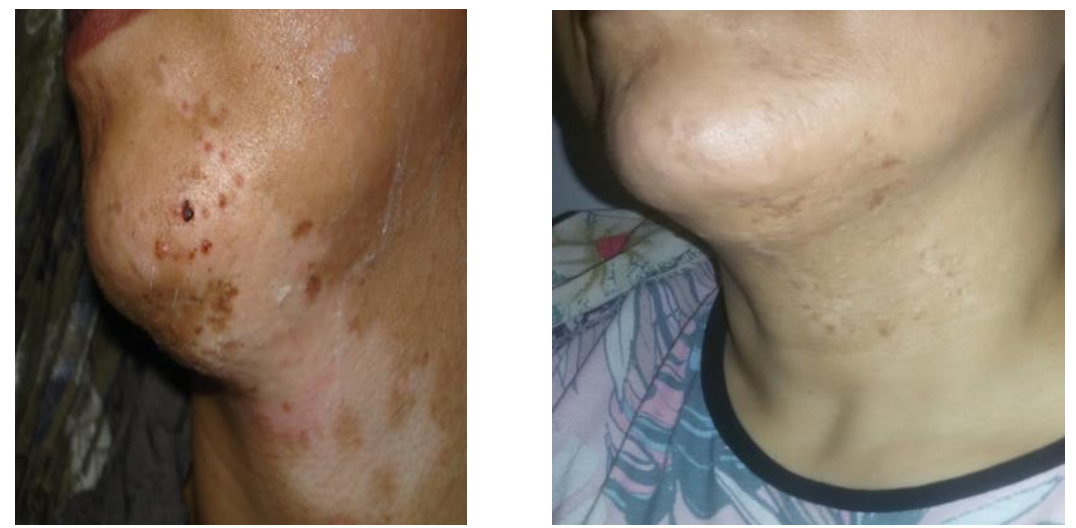

Figure 3: a- Thirty nine years old female patient with segmental vitiligo patch on the chin\& anterior neck. b- The same patient with marked repigmentation after 5 years
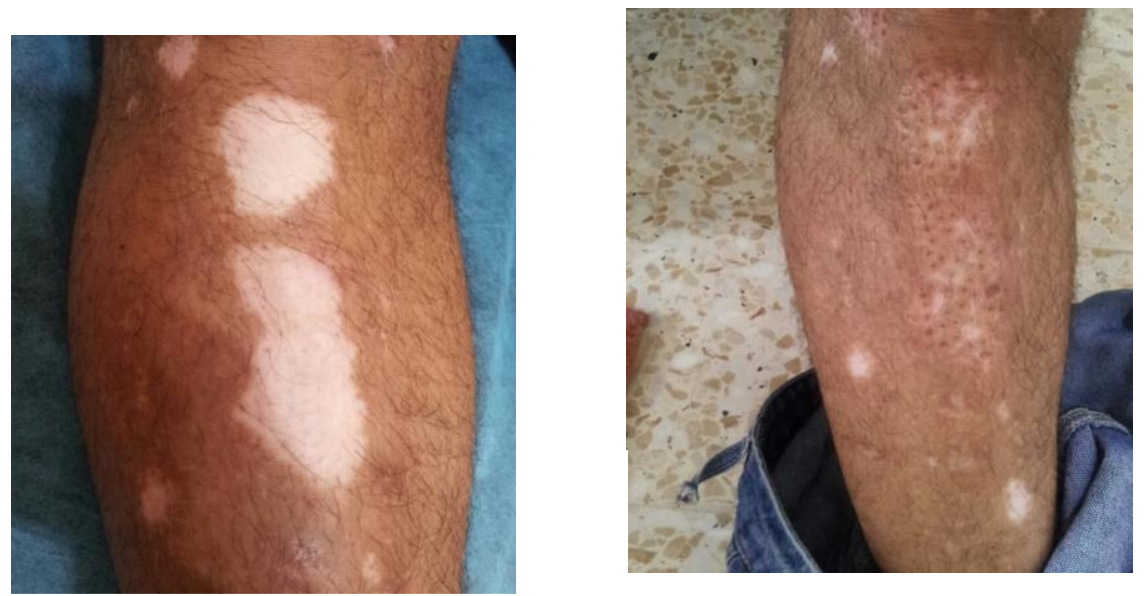

Figure 4: a-Depigmented patches on right leg.$b$ - Perigraft repigmentation 

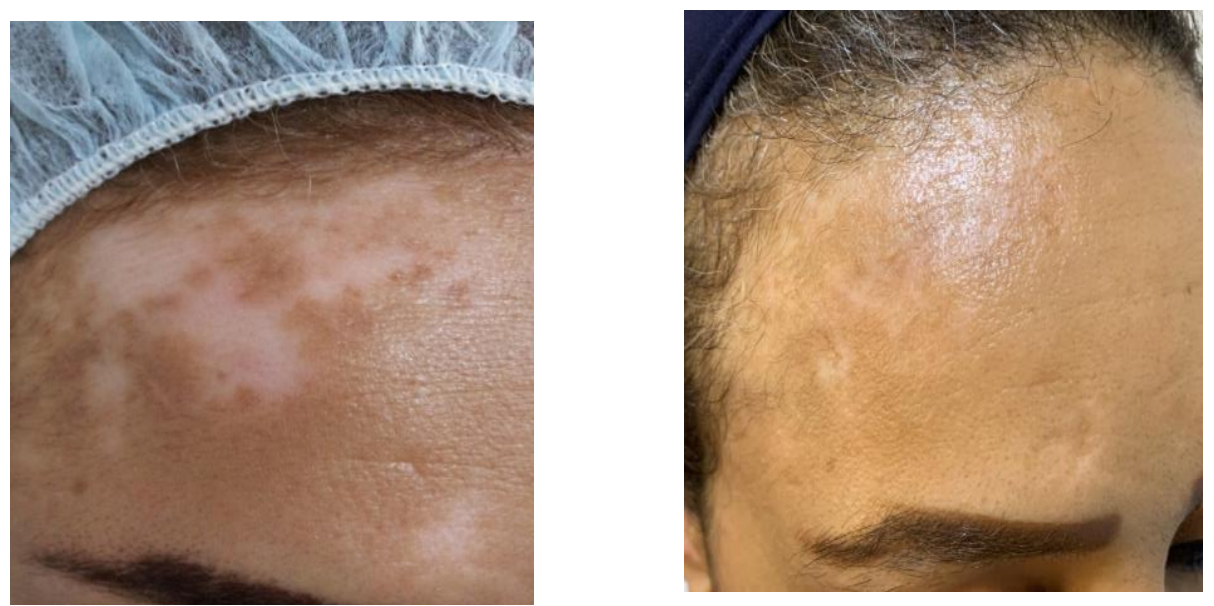

Figure 5: a- female patient with segmental vitiligo on forehead for 20years duration. b- Follow up picture after 4 years with excellent repigmentation.
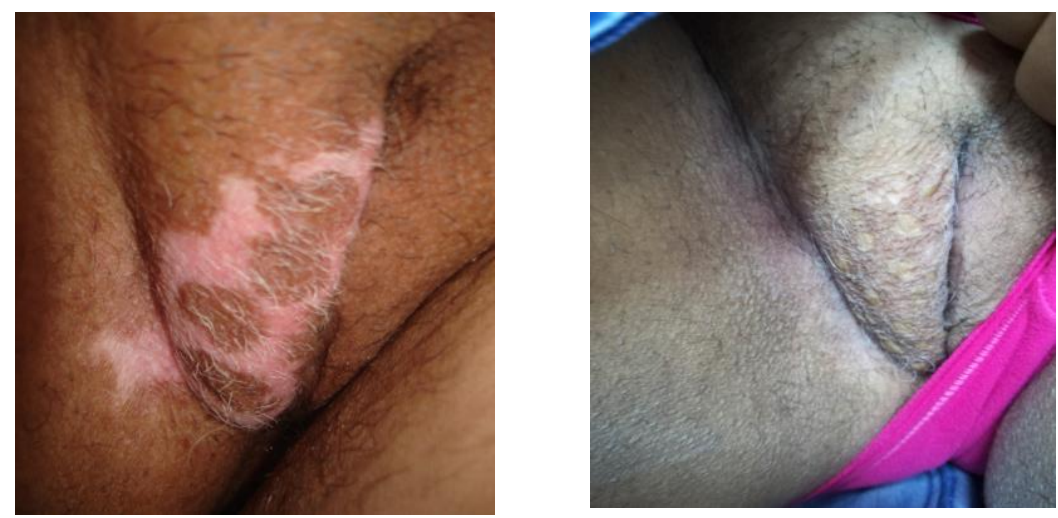

Figure 6: a- Unifom perigraft repigmenation aftter5 weeks on right labia majora\&upper inner thigh. $b$ - Repigmentation with residual flattening cobble stone

Recurrence and progression of the disease may be related to the associated autoimmune disease due to the clinical stability is important in patient's selection [37]. Studies have demonstrated that clinical stability does not always exclude the presence of an autoimmune disease process in patients with vitiligo. Roa et al. 2012 demonstrated an increase in the quantity of the TCD8 ${ }^{+}$and $\mathrm{CD} 5 \mathrm{RO}^{+}$lymphocytes in the vitiligo lesions and this was related to the lower stability and worse response to treatment melanocytes transplants [38].

Perigraft halo means the rim of depigmentation that remains at the outer edge of the vitiligo lesion in case of miniature punch grafting. It was reported in our study that peri graft halo was $50 \%$ which can be avoided or minimized by a proper surgical technique. The technique involves placing the grafts along the periphery first before going towards the center of the lesion to be treated.

The complication cobblestone appearance was decreased by using $2 \mathrm{~mm}$ punch, and was decreased with the time, and in resistant cases we used dermovate cream under occlusion [39]. At the donor sites no infection or keloid have appeared mostly after healing with secondary intention minimal superficial scaring is expected and acceptable.

\section{CONCLUSIONN}

Most vitiligo patients obtained some degree of improvement in transplanted sites with autologus punch minigrafting followed by khelline solution, sun exposure, and immunomodulators in some patients. Further 
prospective studies on larger number of patients should be done to determine the effect of stability of pigmentation achieved by this combination regimen. We suggest that mini grafting to be used as treatment for patients with stable vitiligo using a small size punch, that is less than $2 \mathrm{~mm}$.

\section{REFERENCES}

1. Parsad D, Dogra S, Kanwar AJ. Quality of life in patients with vitiligo. Health Quality Life Outcomes. 2003;1:58.

2. Niti Khunger, Sushruta Dash Kathuria, and V. Ramesh TISSUE GRAFTS IN VITILIGO SURGERY - PAST, PRESENT, AND FUTUREIndian J Dermatol. 2009 Apr-Jun; 54(2): 150-158.

3. Behl PN. Treatment of vitiligo with homologous thin Thiersch grafts. Curr Med Pract. 1964;8:218-21

4. Falabella R. epidermal grafting: An original technique and its application in achromic and granulating areas. Arch Dermatol. 1971;104:592-600.

5. Falabella R. Repigmentation of leucoderma by minigrafts of normally pigmented, autologous skin. J Dermatol Surg Oncol. 1978;4:916-9

6. Falabella R, Escobar C, Borrero I. Transplantation of in-vitro cultured epidermis bearing melanocytes for repigmenting vitiligo. J Am Acad Dermatol. 1989;21:257-66.

7. Gauthier Y, Surleve-Bazeille JE. Autologous grafting with non-cultured melanocytes: A simplified method for treatment of depigmented lesions. J Am Acad Dermatol. 1992;20:191-4.

8. Olsson M, Juhlin L. long-term follow-up of leukoderma patients treated with transplants of autologous cultured melanocytes, ultrathin epidermal sheets and basal cell layer suspension. $\mathrm{Br}$ J Dermatol. 2002;47:893-904.

9. Kahn AM, Cohen MJ. Repigmentation in vitiligo patients: Melanocyte transfer via ultra-thin grafts. Dermatol Surg. 1998;24:365-8.

10. Kahn AM, Ostad A, Moy RL. Grafting following short pulse CO2 laser de-epithelialization. Dermatol Surg. 1996;22:965-7.

11. Lahiri K, Malakar S, Sarma N, Banerjee U. Repigmentation of vitiligo with punch grafting and narrow-band UV-B (311 nm) a prospective study. Int J Dermatol. 2005;45:649-55.

12. Orentriech N, Selmanwitz VJ. Autograft repigmentation of leucoderma. Arch Dermatol. 1972;105:784-6.

13. Labuono P, Shatin H. Transplantation of hair bulbs and melanocytes into leucodermic scars. J Dermatol Surg Oncol. 1976;2:53-5.

14. Malakar S, Lahiri K. Minigrafting for vitiligo. In: Gupta S, Olsson MJ, Kanwar AJ, Ortonne JP, editors. Surgical management of vitiligo. 1st ed. Oxford: Blackwell Publishing; pp. 87-95. [Google Scholar]

15. Falabella R. Repigmentation of segmental vitiligo by autologous mimigrafting. J Am Acad Dermatol. 1983;9:514-21.

16. Malakar S. An Approach to Dermatosurgery. 1st ed. Calcutta: A Paul; 1996. Punch Grafting; pp. 44-6.

17. Malakar S, Dhar S. Treatment of stable and recalcitrant vitiligo by autologous mimiature punch grafting: A prospective study of 1,000 patients. Dermatology. 1999;198:133-9.

18. Torium DM, O'Grody K, Desai D, Bagal A. Cyanoacrylate Adhesive. Plast Reconstr Surg. 1998; 102:2209-19.

19. Skouge JW, Morison WL, Diwan RV, Rotter S. Autografting and PUVA: A combination therapy for vitiligo. Dermatol Surg Oncol. 1992; 18:357-60.

20. Hann SK, Im S, Bong HW, Park YK. Treatment of stable vitiligo with autologous epidermal grafting and PUVA. J Am Acad Dermatol. 1995; 32:943-8.

21. Lahiri K, Sengupta SR. Treatment of stable and recalcitrant depigmented skin conditions by autologous punch grafting. Indian J Dermatol Venereol Leprol. 1997;63:11-4.

22. Olsson MJ, Juhlin L. Repigmentation of Vitiligo by transplantation of cultured autologous melanocytes. Acta Derm Venereol (Stockh) 1993; 73:49-51. 
23. Malakar S, Lahiri K. Punch grafting for lip leucoderma. Dermatology. 2004; 208:125-8.

24. Malakar S, Lahiri K. Electrosurgery in cobblestoning. Indian J Dermatol. 2000; 45:46-7.

25. Falabella R. Surgical treatment of Vitiligo: Why, when and how. J Eur Acad Dermatol Venereol. 2003; 17:518-20.

26. Whitton MF, Pinar t M, Batchelor J, Leonardi-Bee J, González, U, Jiyad Z, et al. Interventions for vitiligo. Cochrane Database Syst Rev. 2015:CD003263.

27. Boza JC, Kundu RV, Fabbrin A, Horn R, Giongo N, Cestari TF. Translation, cross-cultural adaptation and validation of the vitiligo-specific-related quality of life instrument (VitiQoL) into Brazilian Portuguese. An Bras Dermatol. 2015;90:358-62.

28. Nogueira LSC, Zancanaro PCQ, Azambuja RD. Vitligo e emoções. An Bras Dermatol. 2009; 84:41-41-5.

29. Das SS, Pasricha JS. Punch grafting as atreatment for residual lesions in vitiligo. Indian J Dermatol Venereol Leporol. 1992;58:315-9.

30. Jha AK, Pandey SS, Shukla VK. Punch grafting in vitiligo. Indian J Dermatol Venereol Leporol. 1992;58:328-30.

31. Ortel B ${ }^{1}$,Tanew A, Hönigsmann H. Treatment of vitiligo with khellin and ultraviolet A. J Am Acad Dermatol. 1988 Apr;18(4 Pt1):693-701

32. Abdel- Fattah, M N Aboul-Enein, G M Wassel, B S El-Menshawi An Approach to the Treatment of Vitilido by khellin Dermatologica. 1982 Aug; 165(2):136-40.

33. Farajzadeh S, Daraei Z, Esfandiarpour I, Hosseini SH. Pediatr Dermatol The efficacy of pimecrolimus $1 \%$ cream combined with microdermabrasion in the treatment of nonsegmental childhood vitiligo: a randomized placebo-controlled study. 2009 May-Jun;26(3):286-91.

34. Chun, W H., Hann, S.K.(1997) The progression of nonsegmental vitligo: clinical analysis of 318 patients. Int. J. Dermatol., 36 (12), 908-910.

35. Savant SS. Autologous miniatures punch grafting in vitiligo. Indian J Dermatol Venereol Leprol. 1992;58:310-4.

36. Bao H, Hong W, Fu L, Wei X, Qian G, Xu A. Blister roof grafting, cultured melanocytes transplantation and non-cultured epidermal cell suspension transplantation in treating stable vitiligo. A mutual self -control-study. J Dermatology Treat. 2015;26:571-4

37. Fongers A, Wolkerstorfer A, Nieuweboer-Krobotoval, Krawczyk P, Toth, van der Veen JP.Long- term results of $2 \mathrm{~mm}$ punch grafting in patients with vitiligo vulgaris and segmental vitiligo: effect of disease activity.BrJ Dermatol. 2009Nov;161(5):1105-11.

38. Roa A, Gupta S, Dinda AK, Sharma A, Sharma VK, Kumar G, et al. Study of clinical,biochemical and immunological factors determining stability of disease in patients with generalized vitiligo undergoing melanocyte transplantation. Br J Dermatol. 2012;166:1230-6.

39. Norazirah Md Nor, Rasimah Ismail, Adawiyah Jamil, Shamsul Azhar Shah, Farah Hani Imran A Randomized, Single-Blind Trial of Clobetasol Propionate $0.05 \%$ Cream Under Silicone Dressing Occlusion Versus Intra- Lesional Triamcinolone for treatment of keloide 2017 Mar;37(3):295-301. 